\title{
O33 I Patterns of viral suppression on CART as predictors of uncontrolled viremia after starting a new antiretroviral after I January 2003
}

\author{
J Reekie*1, A Mocroft ${ }^{1}$, B Ledergerber ${ }^{2}$, M Beniowski ${ }^{3}$, B Clotet ${ }^{4}$, J van \\ Lunzen $^{5}$, A Chiesi ${ }^{6}$, C Pradier ${ }^{7}$, L Machala ${ }^{8}$ and JD Lundgren ${ }^{9}$
}

\begin{abstract}
Address: ${ }^{1}$ Royal Free \& University College Medical School, London, UK, ${ }^{2}$ University Hospital, Zurich, Switzerland, ${ }^{3}$ Osrodek Diagnostyki i Terapii AIDS, Chorzow, Poland, ${ }^{4}$ Hospital Germans Trias i Pujol, Badalona, Spain, ${ }^{5}$ University Medical Center Hamburg-Eppendorf, Infectious Diseases Unit, Hamburg, Germany, ${ }^{6}$ Istituto Superiore di Sanità, Rome, Italy, ${ }^{7}$ Hôpital de l'Archet, Nice, France, ${ }^{8}$ Faculty Hospital Bulovka, Prague, Czech Republic and ${ }^{9}$ Copenhagen HIV Programme, Panum Institute, Copenhagen, Denmark

* Corresponding author
\end{abstract}

from Ninth International Congress on Drug Therapy in HIV Infection

Glasgow, UK. 9-13 November 2008

Published: 10 November 2008

Journal of the International AIDS Society 2008, I I (Suppl I):O35 doi:I0.1 I86/I758-2652-I I-SI-O35

This abstract is available from: http://www.jiasociety.org/content/I I/SI/O35

(c) 2008 Reekie et al; licensee BioMed Central Ltd.

\section{Purpose of the study}

We aimed to investigate which measures of prior viral suppression predicted uncontrolled viremia in patients on cART who started $>1$ antiretrovirals (ARV) after 1/1/2003.

\section{Methods}

1,807 EuroSIDA patients on cART that started any ARV after January 1, 2003 were included. Baseline was defined as the date of starting a new ARV after January 1, 2003. Poisson regression, adjusted for appropriate confounding variables, was used to identify measures of viral suppression before baseline which predicted risk of uncontrolled viremia (viral load $[\mathrm{VL}]>500$ copies $/ \mathrm{ml}$ at least 6 months after baseline) after starting a new ARV. Measures of viral suppression before baseline were number of rebounds (VL $>500$ copies $/ \mathrm{ml}$ ), size of rebounds, time since last rebound, highest ever rebound, and the total time suppressed and percentage of time suppressed while on cART prior to baseline.

\section{Summary of results}

At baseline patients had been on CART a median of 6.2 years (IQR 4.7-7.3), and had been exposed to a median of seven ARVs (IQR 5-9). The most common reasons for starting a new ARV was patient/physician choice (32\%) and toxicities (31\%); 66\% were suppressed at baseline.
530 patients experienced uncontrolled viremia (400 whilst on CART) after starting a new ARV. The incidence of uncontrolled viremia was $13.7 / 100$ PYFU $(95 \%$ CI:12.5-14.9). Figure 1 show the crude incidence of uncontrolled viremia after stratification by the number of rebounds and the proportion of time fully suppressed while on cART prior to baseline. In adjusted models, the rate of uncontrolled viremia was lower in those with fewer viral rebounds before baseline (IRR per additional prior rebound $=1.12$ (95\% CI: $1.04-1.20)$, and with increasing time fully suppressed on cART prior to baseline (IRR per additional $10 \%$ suppressed $=0.86(0.83-0.90)$. Higher rebound values and less time since last rebound also increased the risk of uncontrolled viremia but were not significant after adjustment for time suppressed and number of previous rebounds. The results were consistent between patients suppressed and unsuppressed at baseline.

\section{Conclusion}

The number of previous rebounds and the percentage of time suppressed whilst on CART were both strong predictors of future uncontrolled viremia after starting a new ARV. Hence, the history of patterns of viral response to cART regimens should be an integrated component in 
Figure 1a

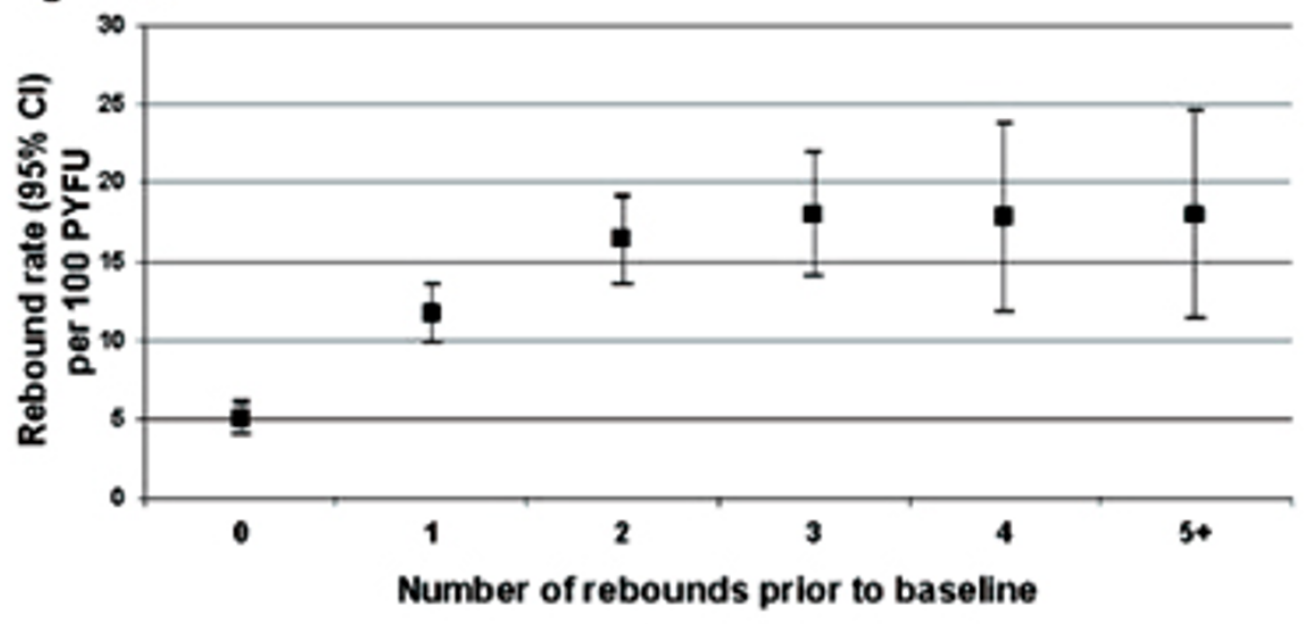

\begin{tabular}{|l|c|c|c|c|c|c|}
\hline No of rebounds prior to baseline & 0 & 1 & 2 & 3 & 4 & $5+$ \\
\hline No rebounded after baseline & 91 & 161 & 135 & 81 & 34 & 28 \\
\hline PYFU & 1814 & 1373 & 825 & 451 & 191 & 156 \\
\hline
\end{tabular}

Figure 1b

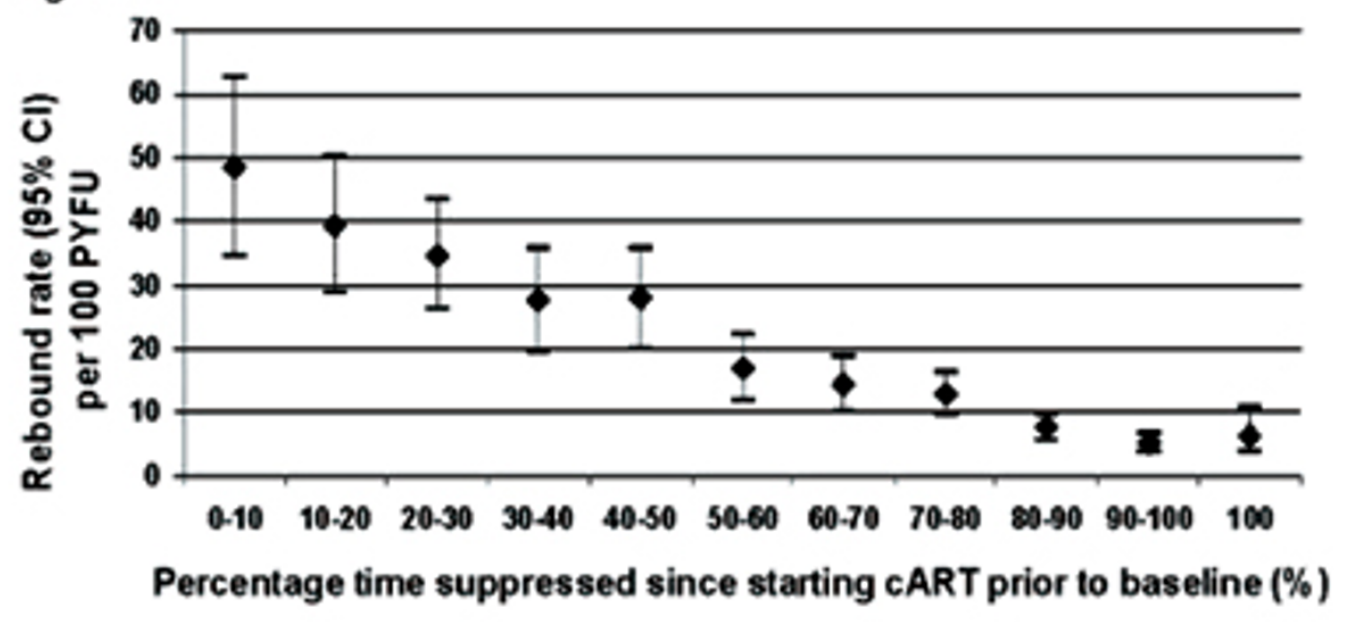

\begin{tabular}{|l|l|l|l|l|l|l|l|l|l|l|l|}
\hline $\begin{array}{l}\text { \%ime succressed pricr to } \\
\text { baseline }\end{array}$ & $<10$ & $10-20$ & $20-30$ & $30-40$ & $40-50$ & $50-60$ & $60-70$ & $70-80$ & $80-90$ & $90-100$ & 100 \\
\hline No rebounced afer boseine & 47 & 53 & 62 & 44 & 47 & 42 & 43 & 62 & 56 & 59 & 15 \\
\hline PrFU & 96 & 134 & 178 & 159 & 169 & 247 & 298 & 479 & 735 & 1141 & 233 \\
\hline
\end{tabular}

Figure I 
deciding monitoring strategies and adherence counseling for patients whenever a change in cART is made.

Publish with Biomed Central and every scientist can read your work free of charge

"BioMed Central will be the most significant development for disseminating the results of biomedical research in our lifetime. " Sir Paul Nurse, Cancer Research UK

Your research papers will be:

- available free of charge to the entire biomedical community

- peer reviewed and published immediately upon acceptance

- cited in PubMed and archived on PubMed Central

- yours - you keep the copyright

Submit your manuscript here:

http://www.biomedcentral.com/info/publishing_adv.asp 